\title{
Processo de governança e gestão financeira: estudo em uma universidade de base comunitária/pública da região do vale do Itajaí, Santa Catarina, Brasil
}

\author{
Ronaldo Leão de Miranda ${ }^{1}$ \\ Maria Jose Carvalho de Souza Domingues ${ }^{2}$
}

\begin{abstract}
RESUMO
O objetivo deste estudo está pautado em descrever o processo de governança e de gestão financeira adotado por uma universidade brasileira de base comunitária/pública localizada na região do vale do Itajaí -SC. Metodologicamente, a pesquisa caracteriza-se como descritiva em relação a seu objetivo, quanto aos procedimentos pode ser considerada como pesquisa aplicada a partir do levantamento de dados primários e secundários e qualitativa em relação à abordagem do problema, sendo analisada por meio da análise de conteúdo. Quanto aos resultados, tem-se que $80 \%$ da receita da IES advém das mensalidades dos alunos e os outros $20 \%$ do artigo 170 e 171, financiamento estudantil (FIES), além da prestação de serviço. No que se refere a governança, tem em sua organização a gestão superior (Reitoria) na qual desenha as políticas macro e faz o controle dos processos financeiros. Quando se trata das vantagens competitiva da universidade, pode-se salientar que a mesma gera muito conhecimento, muita inserção na sociedade, mas de resultado financeiro muito pouco. Tem-se, portanto, que a universidade precisa fortalecer e melhorar a graduação, através de novos projetos pedagógicos, que contemple as necessidades dos seus alunos, pesquisa e extensão universitária. Por fim, como estratégia da universidade para superar o atual mercado competitivo do ensino superior, é importante se ter uma governança bem estruturada e participativa bem como um processo de gestão financeira eficiente, com isso, a tomada de decisão fica mais ágil e as metas podem ser projetadas de forma eficaz.
\end{abstract}

Palavras-chave: Processo de governança; Gestão Financeira; Universidade; Gestão Universitária.

\section{Governance and financial management process: study in a community/public university in the vale do itajaí region, Santa Catarina, Brazil}

\begin{abstract}
The aim of this study is to describe the governance and financial management process adopted by a Brazilian university with a community / public base located in the region of the Itajaí valley - SC. Methodologically, the research is characterized as descriptive in relation to its objective, as for the procedures it can be considered as applied research from the survey of primary and secondary data and qualitative in relation to the approach of the problem, being analyzed through content analysis . As for the results, $80 \%$ of the HEI's revenue comes from student fees and the other 20\% from article 170 and 171, student financing (FIES), in addition to the provision of services. With regard to governance, it has in its organization top management (Rectory) in which it designs macro policies and controls financial processes. When it comes to the university's competitive advantages, it can be noted that it generates a lot of knowledge, a lot of insertion in society, but very little financial result. There is, therefore, that the university needs to strengthen and improve the graduation, through new pedagogical projects, that contemplate the needs of its students, research and university extension. Finally, as a university strategy to overcome the current competitive higher education market, it is important to have a well-structured and participatory governance as well as an efficient financial management process, with this, decision making becomes more agile and goals can be designed effectively.
\end{abstract}

Keywords: Governance process; Financial management; University; University Management.

\footnotetext{
1 Bacharel em Administração. Mestre em Desenvolvimento Regional. Doutorando pelo Programa de PósGraduação em Ciências Contábeis e Administração da Universidade Regional de Blumenau (PPGCC-AD/FURB). E-mail: ronaldo_leaomiranda@hotmail.com

${ }^{2}$ Graduação em Ciências da Administração, Mestrado em Administração pela Universidade Federal de Santa Catarina e Doutorado em Engenharia de Produção pela Universidade Federal de Santa Catarina. Professora titular da Universidade Regional de Blumenau/FURB, no Departamento de Administração. mariadomingues@ furb.br
} 


\section{INTRODUÇÃO}

As instituições de ensino superior (IES) têm sido ao longo do tempo a principal indutora e difusora de desenvolvimento e de conhecimento científico. $\mathrm{Na}$ área da administração universitária, as contribuições através do conhecimento são vastas, possibilitando e oferecendo aos gestores ferramentas que auxiliam na tomada de decisão. No entanto, apesar da evolução do conhecimento em administração universitária, as formas de gestão continuam tendo o foco principal no debate (BUSH, 2007). Neste contexto, pode-se ressaltar que há investigações recentes que apontam que o debate sobre gestão em IES possui uma grande relevância no campo da pesquisa (RODRÍGUEZ-PONCE et al., 2017).

Como um dos temas desta pesquisa é a gestão financeira em IES, vale ressaltar a importância desta temática de pesquisa, pois a gestão financeira visa garantir a sustentabilidade e a manutenção da organização. Pode-se dizer, portanto, que a gestão financeira é um dos meios que auxiliam os gestores educacionais na avaliação dos investimentos e tomadas de decisões. Independente da forma jurídica da IES, seja pública ou privada, com ou sem fins lucrativos, todas demandam um modelo de gestão financeira (QUEIROZ; QUEIROZ; HÉKIS, 2011). Quanto a governança, outro tema a ser debatido neste estudo, pode-se salientar que se trata de um conceito relativamente novo, que permeia o campo da gestão universitária (FOLETTO; TAVARES, 2014).

As instituições de ensino superior, comunitária, tem assumido ao longo do tempo no âmbito da gestão, modelos e práticas empresariais. Práticas estas que foram adotadas após a abertura do segmento de ensino superior privado no Brasil, com isso, foi preciso pensar uma nova forma de gestão para as IES (FOLETTO; TAVARES, 2014). Um dos pontos críticos para a adoção deste tipo de gestão tem sido ocasionado pelo fato da inexistência de um modelo de gestão específico para IES. O fato de inexistir tal modelo ou teoria, tem impulsionado os gestores das IES a buscarem conhecimentos e práticas utilizadas no setor empresarial, se concentrando na essência da teoria administrativa (MEYER JR, 2014).

A aplicação destes tipos de gestão está pautada na excelência dos diversos modelos de gestão empresarial, o qual proporcionam eficiência na gestão financeira das IES. Estes estilos de gestão, se incorporam em vários tipos e áreas das instituições de ensino superior, Brasil afora (MEYER JR, 2014). Um dos tipos de IES que se utilizam deste tipo de gestão são as pertencentes ao terceiro setor (comunitárias). As universidades comunitárias possuem algumas especificidades na gestão, estão inseridas entre o público e o privado, com foco predominante 
no atendimento de demandas sociais. Neste sentido, se requer tipos próprios de governança e de gestão, devido à complexidade na articulação dos interesses entre doadores, financiadores, mantenedores, voluntários, funcionários, beneficiários e comunidades (TAVARES, 2009).

Diante da pluralidade, as universidades comunitárias vêm ao longo do tempo conquistando seu espaço de atuação e tem na governabilidade um de seus principais desafios de atuação. Em meio ao recente processo de concorrência instalado com o rápido crescimento das instituições universitárias mantidas por entidades com fins lucrativos, as IES de base comunitárias tem se adaptado dia após dia (TAVARES, 2009). Neste sentido, trabalhar estes temas, gestão financeira e governança universitária, se justifica mais uma vez pela escassez de tais abordagens na literatura vigente. Neste sentido, desenvolver e incentivar pesquisas sobre essas duas temáticas, poderá contribuir ainda mais tanto para a dimensão acadêmica quanto para fins institucionais e sociais. A pergunta norteadora a ser respondida neste estudo é como ocorre o processo de governança e de gestão financeira na qual é adotada por uma universidade de base comunitária/pública?

Nesta perspectiva, esta pesquisa se propôs a descrever o processo de governança e de gestão financeira adotada por uma universidade brasileira de base comunitária/pública localizada na região do vale do Itajaí -SC. Sendo assim, perante as justificativas, busca-se elucidar e analisar o processo de governança e de gestão financeira, a partir dos seguintes objetivos específicos: a) Como se dá a obtenção de recursos financeiros pela instituição de ensino superior? b) Dentro de uma estrutura de governança, como são tomadas as decisões de investimentos? c) Como funciona o planejamento e controle financeiro da instituição? e d) Como se encontra a liquidez, a solvência e rentabilidade da instituição?

Perante a este exposto introdutório, o artigo encontra-se estruturado da seguinte forma: próxima seção, apresenta-se a revisão da literatura, abordando conceitos sobre governança, governança aplicada ao terceiro setor / organizações sem fins lucrativos, gestão financeira em IES; na terceira seção, descreve-se os procedimentos metodológicos utilizados na pesquisa; na quarta seção, apresentam-se os resultados do estudo; na quinta seção, tecem-se as considerações finais do estudo, incluindo suas limitações e sugestões de futuras pesquisas.

\section{REVISÃO DA LITERATURA}

A base teórica empregada neste estudo encontra-se subdividida em: conceitos sobre governança, governança aplicada ao terceiro setor / organizações sem fins lucrativos, gestão financeira em IES. 


\subsection{Conceitos de Governança}

As discussões ligadas a governança empresarial tiveram sua origem em 1930, porém, somente nos anos de 1980 que o debate em si se tornou intenso devido a uma série de acontecimentos, especialmente após os escândalos corporativos do final do século XX e início do século XXI (BERLE; MEANS, 1932; SILVA et al., 2015). Com isso, o conceito de governança aponta para a criação de uma estrutura na qual não pode ser imposta, mas sim que seja resultante da interação contínua entre governantes e outros atores envolvidos. O interesse em relacionar a governança com algum tipo de ordem resulta em uma definição ampla de governança, na qual pode-se referir a qualquer modo de coordenação de atividades interdependentes, em que inclui instituições públicas e instituições privadas. (KOOIMAN; VAN VLIET,1993; JESSOP,1998).

Neste sentido, Tavares (2009) salienta que o termo governança tem sido utilizado em diferentes campos, sendo que um deles vem da administração, com o sentido de governança corporativa, e consiste nas práticas e nos relacionamentos entre os acionistas, o conselho de administração e os demais órgãos da organização. A governança pode ser entendida como um aprimorado sistema de gestão que trata do processo decisório e dos relacionamentos que a organização possui com seus stakeholders (IBGC, 2009; SILVEIRA, 2010; SILVA et al., 2015). A BM\&FBOVESPA (2018) expõe que a governança é um conjunto de mecanismos que serve para incentivar e monitorar o processo decisório para o alcance das metas estratégicas e criação de valor.

Neste sentido, as boas práticas de governança visam o alinhamento dos interesses, a melhoria no desempenho da gestão, bem como a agregação de valor perante o mercado (SLOMSKI et al., 2008). Dessa forma, a Organização para a Cooperação e Desenvolvimento Económico (OCDE) tem como princípios fundamentais de governança, a garantia de uma estrutura efetiva, os direitos dos acionistas, o tratamento equitativo dos acionistas, o papel dos stakeholders, a divulgação e a transparência dos demonstrativos e a responsabilidade do conselho. A partir dos princípios da OCDE o IBGC (2015) dispõe de quatro princípios básicos para a governança corporativa: a transparência (disclosure); a prestação de contas (accountability); a equidade (fainerss) e a responsabilidade corporativa (corporate responsibility). 
Para tornar-se eficaz o sistema de governança numa dada organização é fundamental a combinação de diferentes mecanismos de controle internos e externos (SILVA et al., 2015). Dentre os mecanismos de controle externos estão: a proteção legal, a fiscalização dos agentes de mercado, a competição no mercado de trabalho de executivos e a estrutura de capital (SILVEIRA, 2010). Já no que tange aos mecanismos internos estão a assembleia geral, o conselho de administração, o conselho fiscal, o sistema de remuneração, normas internas, planos estratégicos da organização, dentre outros (ROSSETTI; ANDRADE, 2011).

Para Silva et al. (2015) a boa governança possibilita aos proprietários a gestão estratégica da organização e o monitoramento da diretoria através de três principais mecanismos: conselho de administração, conselho fiscal e auditoria independente. Dessa forma, cabe ao conselho de administração estabelecer o direcionamento estratégico para a diretoria executiva elaborar as políticas organizacionais e o plano estratégico da organização. Somente após a aprovação do conselho, que a diretoria coloca em execução o que foi planejado. A partir do momento que a diretoria põe em prática as ações na organização, deve o diretor-presidente prestar contas para o conselho de administração, sendo este o processo dentro das organizações (ROSSETTI; ANDRADE, 2011; IBGC, 2015; SILVA et al., 2015). A figura 1 esboça as etapas do processo de decisão na organização.

Figura 1: Etapas do processo de decisão e governança na organização

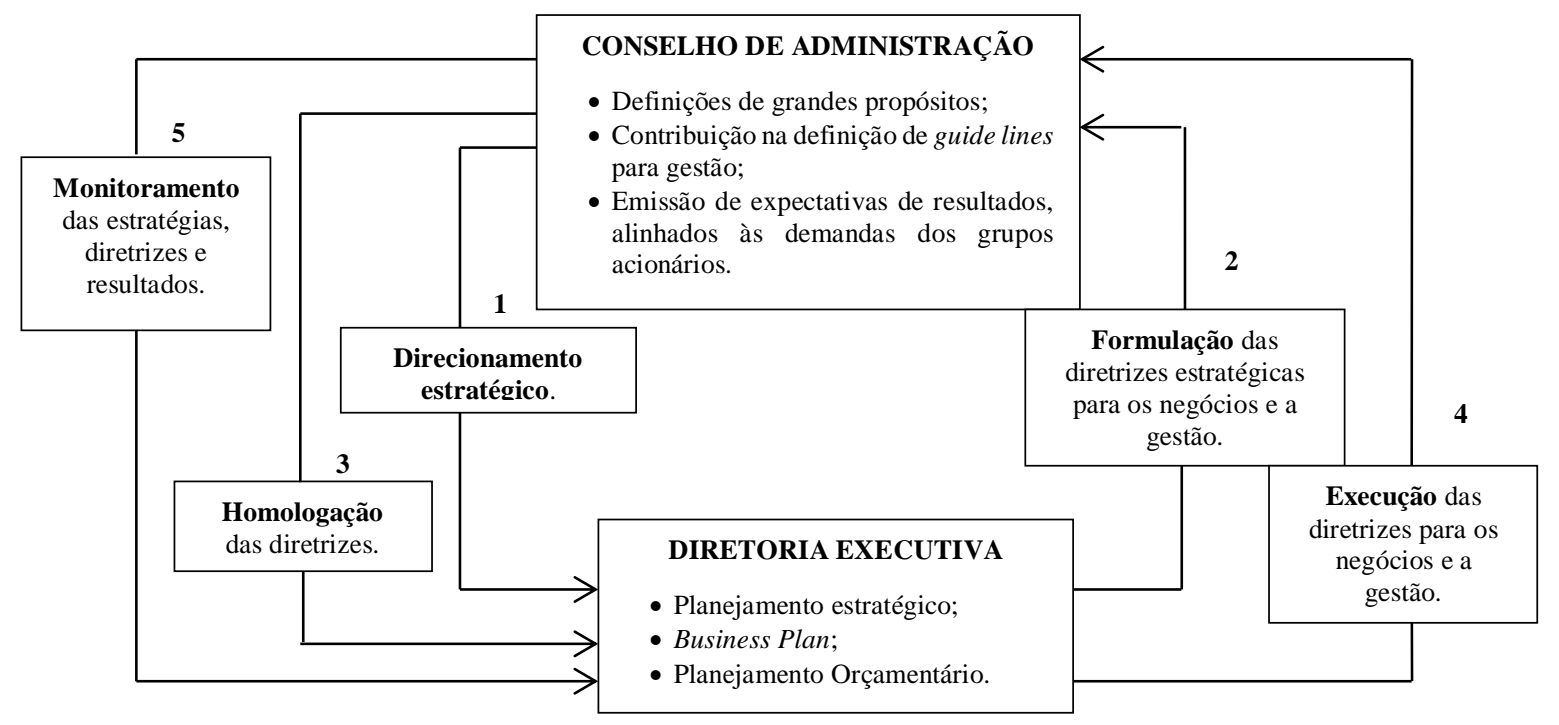

Fonte: Rossetti e Andrade (2011, p.140).

Como pode ser observado na figura 1 , o conselho de administração é considerado o principal mecanismo de governança, uma vez que ele é o elo entre a propriedade e a gestão (SLOMSKI et al., 2008). O conselho de administração exerce um papel essencial na fixação de 
estratégias e no monitoramento das ações da diretoria, para que assim se alcance os objetivos e metas traçados pela organização (SILVA et al., 2015). Como órgãos de acessória vinculados ao conselho de administração, a organização pode formar comitês especializados, por exemplo, comitê de auditoria, de governança, de ética, de finanças, dentre outros.

Cada comitê deve estudar os assuntos relativos à sua competência e elaborar propostas a serem apresentadas para o conselho de administração (HILB, 2009). Se utilizando da teoria de governança para fundamentar o estudo, o tópico seguinte, irá abordar conceitos de governança do terceiro setor / organizações sem fins lucrativos e o modelo de governança que a IES objeto de estudo exerce.

\subsection{Governança Aplicada ao Terceiro Setor / Organizações sem Fins Lucrativos}

As organizações do terceiro setor são responsáveis por uma parte vultosa e crescente da atividade econômica. Essas organizações com o passar do tempo vêm mudando o cenário do ambiente econômico. As organizações do terceiro setor são essenciais e trazem consigo os valores e a tradição da sociedade civil. Logo o que parece incomodar aos que atuam no terceiro setor há um tempo é o espaço ocupado por organizações de atuação empresarial, tendo em vista que as mesmas chamam atenção do público e disputam recursos que antes distribuídos entre menor número de competidores (SATHLER; FISCHE, 2008).

Buscando regulamentar estas organizações, algumas leis foram criadas para monitorar, regulamentar e classificar as organizações do terceiro setor. A lei de $\mathrm{n}^{\circ} 9.637$ de 15 de maio de 1998, define que o poder executivo poderá qualificar pessoas jurídicas de direito privado, sem fins lucrativos atividades que sejam de ensino, pesquisa científica, desenvolvimento tecnológico, proteção e preservação do meio ambiente, cultura e saúde. Neste sentido, a concessão de organizações do terceiro setor é regulada e monitorada pelo governo federal.

A lei exige alguns requisitos específicos para que as entidades privadas habilitem-se a qualificação de organização social, dentre elas: finalidade não-lucrativa, obrigatoriedade de investimento de seus excedentes financeiros no desenvolvimento das próprias atividades; previsão expressa de a entidade ter como órgãos de deliberação superior e de direção um conselho de administração e uma diretoria definida nos termos do estatuto; obrigatoriedade de publicação anual no diário oficial da união os relatórios financeiros (BRASIL, 1998). 
Diante da exposição dos conceitos sobre a estrutura e importância das organizações do terceiro setor para a sociedade civil, parte-se para as abordagens ligadas a gestão financeira em IES.

\subsection{Gestão Financeira em IES}

A gestão financeira das Instrituições de Ensino Superior (IES) devem ser realizadas a fim de garantir a sua sustentabilidade. Neste sentido, a gestão financeira é um meio composto de diversos indicadores na qual são úteis para a tomada de decisão, capazes de auxiliar os gestores educacionais na avaliação dos investimentos. Neste caso, a gestão financeira assume também um papel de controle, que de forma mais eficaz ajuda no planejamento, análise de investimentos e obtenção de recursos para financiar as operações das IES (GITMAN, 2004). Além disso, a gestão financeira das instituições de ensino superior (IES) estão pautadas na constituição de 1988, quando se trata que as universidades brasileiras gozam de autonomia didático-científica, administrativa e de gestão financeira e patrimonial (BRASIL, 1988).

$\mathrm{Na}$ gestão financeira existem algumas variáveis que são importantes destacar, sendo estas: as decisões de investimentos, o planejamento e o controle financeiro. Já os resultados da gestão financeira se expressam em aspectos como a liquidez, a solvência e a rentabilidade (RODRÍGUEZ-PONCE et al., 2017). Além disso a gestão financeira é um processo com diversas atividades, podendo fazer atráves dela a identificação das necessidades das IES, a análise dos gastos, a preparação dos orçamentos além da interpretação dos resultados financeiros. Dentro deste ponto de vista, Taylor (2013) destaca que no atual e previsível ambiente de ensino superior, busca-se sempre por uma melhor gestão financeira, ponto fundamental para garantir a prosperidade e a sobrevivência de qualquer universidade.

Colaborando na discussão dos conceitos, Mestry (2018) define que a gestão financeira é também um processo de gestão dos recursos da IES, cujo fins é sempre atingir os objetivos da instituição. Neste contexto, uma gestão financeira eficaz, possibilita na tomada de decisão uma boa relação custo-benefício no que tange a uma aquisição apropriada e uma alocação adequada dos recursos da IES (BUSH; HEYSTEK, 2003). A gestão financeira, portanto, tem uma centralidade na gestão universitária. Partindo destes conceitos, no tópico seguinte se aborda os procedimentos metodológicos deste estudo. 


\section{PROCEDIMENTOS METODOLÓGICOS}

Metodologicamente trata-se de um estudo descritivo, documental e estudo de caso. Sendo assim, para se alcançar os objetivos desta pesquisa, foi adotada uma tipologia descrita por Raupp e Beuren (2006) aplicada a estudos sociais aplicados. Quanto aos fins é descritivo, pois apresentou de forma discricionária o processo de governança e de gestão financeira adotado pela universidade, de base comunitária / pública, com sede na região do vale do Itajaí. Para Gil (2017), a pesquisa descritiva tem como objetivo a descrição das características de determinada população, tendo como finalidade a identificação de possíveis relações entre as variáveis.

Quanto aos meios da pesquisa, trata-se de uma investigação documental, pois para obter informações secundária relacionadas a universidade, foram feitas pesquisas nos sítios de internet para se obter informações sobre a situação financeira da universidade estudada. Os principais documentos consultados foram o estatuto, o regimento geral, e os relatórios de demonstrações contábeis através do balanço social. Estudo de caso, pois se utilizou de uma universidade de base comunitária/pública, localizada no vale do Itajaí, estado de Santa Catarina. O universo ou o corpo de análise da pesquisa é toda a universidade, e a amostra é a análise do processo de governança e de gestão financeira executada pela universidade.

Quanto a coleta dos dados, a técnica utilizada foi por meio de um roteiro de entrevista, cujos entrevistados foram o "pró-reitor de administração" e o "reitor da IES". A escolha por tais entrevistados, se deu pela acessibilidade. O roteiro de entrevista foi adaptado do trabalho de Rodríguez-Ponce et al. (2017), intitulado "La relación entre la gestión financiera y la calidad en las instituciones de educación superior". Este roteiro foi aprovado pelo comitê de ética da Universidade Regional de Blumenau (FURB), cujo CAAE é 88772218.7.0000.5370. Além da entrevista foi empregada uma pesquisa bibliográfica, para a elaboração da fundamentação teórica. Quanto ao tratamento dos dados, se deu de forma qualitativa, por meio da análise de conteúdo dos roteiros de entrevistas. Portanto, o próximo tópico, visa apresentar os resultados e discussões.

\section{APRESENTAÇÃO DOS RESULTADOS DO ESTUDO}

Esta seção apresenta os resultados e discussões do estudo, em primeiro momento se descreve algumas peculiaridades internas da universidade estudada. Em um segundo momento 
se apresenta os resultados das quatro dimensões do roteiro de entrevista utilizado para a coleta de dados, segundo a visão dos dois principais entrevistados.

\subsection{Peculiaridades da IES}

Segundo dados oficiais coletados a partir do site, regimento e estatuto da própria universidade, a mesma foi a primeira faculdade do interior do estado de Santa Catarina, criada em 1964, como fruto de um movimento comunitário para tornar mais abrangente o acesso ao ensino superior. Em 1986 a IES foi reconhecida e credenciada pelo Ministério da Educação como Universidade. Em 1995, através da lei complementar municipal nº 80, a Universidade figurou como instituição de ensino superior (IES) criada e mantida por uma Fundação, incluída como órgão autônomo na estrutura administrativa do poder executivo municipal, uma instituição oficial de direito público.

Portanto, a IES é uma autarquia municipal de regime especial, possuindo plena autonomia didático-científica, administrativa e de gestão financeira e patrimonial, conforme disciplina seu Estatuto. A IES tem como missão promover o ensino, a pesquisa, a extensão e a inovação, respeitando e integrando a diversidade cultural, fomentando o desenvolvimento social, econômico e ambiental responsável. A IES busca sempre alcançar a sua missão através da visão na qual está pautada em ser uma universidade pública reconhecida pela qualidade de sua contribuição e inovação na vida regional, nacional e global.

A IES conta hoje com 54 cursos de graduação, 11 cursos de pós-graduação (11 mestrados e 3 doutorados) e a escola técnica. Atualmente a IES conta com um total de 9.780 alunos distribuído em cinco câmpus. São mais de 690 docentes que atuam na instituição, e em torno de 800 servidores técnicos administrativo. A universidade conta com um orçamento anual de 218 milhões de reais. Neste sentido, buscando compreender mais a fundo como ocorre o processo de gestão financeira e de governança, os tópicos $(4.2 ; 4.3 ; 4.4$ e 4.5) irão abordar as dimensões propostas no roteiro de pesquisa destacado nos procedimentos metodológicos.

\subsection{Processo de Obtenção de Recursos Financeiros na Universidade}

Iniciou-se as entrevistas com questões relacionadas ao processo de obtenção de recursos financeiros. Para tanto foram entrevistados o pró-reitor de administração e o reitor da IES. Quando questionado sobre a obtenção dos recursos financeiros, o reitor e o pró-reitor de 
administração destacaram uma particularidade da instituição, possui uma receita privada e um custo público. Atualmente em torno de $80 \%$ da receita da instituição advém das mensalidades dos alunos (graduação, pós-graduação e escola de ensino médio), já os outros $20 \%$ provêm de recursos do artigo 170 e 171 que é do governo do estado de Santa Catarina e do governo federal, financiamento estudantil (FIES), além da prestação de serviço à comunidade civil. Para o reitor, se considerar 8.500 alunos de graduação, em torno de 2.500 possui algum subsídio governamental, FIES principalmente.

Quanto ao FIES, em 2011 a universidade tinha 400 alunos, em 2015 subiu para 3.000 alunos e em 2018 houve uma queda, contando atualmente com 1.500 alunos com financiamento estudantil. O pró-reitor destaca que os recursos advindos por meio do governo estão ficando mais escassos, e pelo fato de ser uma instituição pública municipal a lei não permite se buscar recursos financeiros em instituições financeiras para custeio, somente para infraestrutura, mas que precisa ser aprovado em colegiado essa decisão. Quanto a prestação de serviços à comunidade, $18 \%$ estão relacionados a projetos na qual são financiados pelo CNPq, CAPES, Agência Nacional do Petróleo, Petrobras e FAPESC. Já os outros 2\% advém da prestação serviço, como concursos público, dentre outros ressalta o reitor da universidade.

Quando questionado sobre as políticas institucionais que garantem um processo de obtenção de recursos financeiros, para o pró-reitor de administração, não existe na IES uma política bem definida. Um dos pontos desta fragilidade, está na burocracia, com uma falta de flexibilidade e agilidade. Para mudar essa realidade, seria preciso um outro CNPJ, como uma fundação de apoio, e assim poderia se ter um preço melhor, uma qualidade melhor, os custos de operação seriam mais baixo, com isso geraria uma competitividade maior segundo as palavras do pró-reitor. Já para o reitor, as políticas que existem envolvem principalmente a pesquisa e extensão e recentemente algumas ligadas a inovação. Quanto a pesquisa, há um abono de horas, e assim, o pesquisador busca captar recursos para projetos através de editais públicos e privados.

Como a IES é pública municipal, existe uma lei que possibilita professores tempo integral - TI e horistas a prestarem serviços de consultoria, na qual esse professor recebe $60 \%$ de tudo que ele produz e os outros $40 \%$ é revertido para a IES. Esse modelo de captar recursos através da iniciativa dos professores foi espelhado na iniciativa que existe na Universidade de Campinas (UNICAMP) segundo o reitor. Quanto a extensão, existe um projeto importante que é o SIGAD. O projeto tem por objetivo prestar serviço como elaboração e análise de indicadores econômicos, na qual é solicitado pelas prefeituras dos municípios do vale do Itajaí para a 
tomada de decisão. Como contrapartida, as prefeituras pagam por esse serviço. E por fim, o reitor reitera a política de inovação que está ligada aos registros dos produtos e patentes, e assim a universidade garante um percentual dos recursos que serão gerados.

Quando se trata da estrutura de governança, se questiona do ponto de vista das iniciativas, ou seja, de quem parte as principais decisões para a obtenção de recursos financeiros. Para o reitor, a IES é descentralizada nos aspectos que tange as suas potencialidades, na qual tem em sua organização a gestão superior (Reitoria) que desenha as políticas macro e faz o controle dos processos financeiros, empenho de contas, escritório de projetos, dentre outros mecanismos. Por outro lado, tanto a prospecção e captação das oportunidades, muitas partem do departamento, pois a IES detém de 30 departamentos segundo o reitor. Para o pró-reitor a Pró-Reitoria de Administração (PROAD) possui uma função importante neste processo, mas o reitor reitera que a PROAD tem um papel mais regulatório e de gestão dos recursos, do que proatividade na captação dos recursos.

Quando questionado sobre as técnicas e procedimentos que garantem um ótimo processo de obtenção de recursos financeiros, o reitor e o pró-reitor destacam que as técnicas são as normais, com uma gestão financeira tradicional, não possuindo uma técnica específica para garantir isso. Existem algumas particularidades que eles destacam, que para todos os projetos de captação de recursos que passa por prestação de serviço, existe a obrigatoriedade um cálculo anterior a prestação de tal serviço. Esse cálculo é realizado, para assim se saber, os custos de tais operações bem como o retorno que esse serviço vai gerar, tudo isso porque a universidade não está prestando apenas um serviço, mas vendendo sua marca através da prestação de tais serviços para a sociedade. Existe uma política de prestação de contas, processo esse que precisa ser detalhado, pois se tratar de uma instituição pública. O processo de prestação de contas é importantíssimo, para que em outras oportunidades a universidade possa concorrer sem problemas, sem estar na lista de IES com restrições, destaca o pró-reitor de administração.

Do ponto de vista da obtenção de recursos financeiros em seu modo geral, se questiona se os mesmos contribuem decisivamente para o comprimento dos fins institucionais. Para o pró-reitor muito pouco, destacando que isso é visível quando se tem $80 \%$ da receita da universidade advindo das mensalidades dos alunos tanto de graduação quanto de pósgraduação. Ele destaca ainda os desafios que isso gera, pois quando a universidade detinha de uma grande fatia do mercado de educação superior, estava tranquilo, mas atualmente com a forte concorrência advinda de faculdades privadas, com preços de mensalidades muito baixos, fica difícil de competir e assim compromete a gestão financeira que tem um custo fixo e uma 
receita variável. Para o reitor, tirando o ensino, há sim contribuições principalmente na questão de investimento e manutenção de laboratórios, geração de bolsas de iniciação cientifica e pesquisa de mestrado e doutorado, sendo assim, contribuem decisivamente para os comprimentos dos fins institucionais.

Além disso, uma massiva produção cientifica é gerada via a esses recursos financeiros, sendo importantíssimo para a manutenção dos programas de pós-graduação reitera o reitor. Quanto a qualidade do processo de obtenção de recursos financeiros, questionou-se, se gera uma vantagem competitiva para a instituição. Para o pró-reitor, atualmente muito pouco, pelo fato de outras instituições conseguirem captar recursos de forma mais fácil e ágil do que a universidade, com taxas de juros mais baixa. Quando a universidade consegue algum tipo de recursos, são para alguns projetos de pesquisa e extensão específicos, sendo que estes deixam margens pequenas de retorno (taxa de administração). O pró-reitor reitera que a universidade gera muito conhecimento, muita inserção na sociedade, mas de resultado financeiro muito pouco ainda.

O reitor possui uma visão mais otimista, considerando que sim, quando analisado do ponto de vista de algumas áreas que a universidade possui uma excelência consolidada, ou seja, está muito bem sedimentado. Ele cita-se como exemplo, um departamento da engenharia, na qual constantemente através da qualidade do serviço prestado e da produção cientifica gerada, a obtenção de recursos é quase algo espontâneo, tendo muita facilidade de ser contemplado com editais. Já em relação a outras IES, o diferencial da universidade está na qualidade e o quanto esses recursos financeiros contribuem para uma vantagem competitiva segundo o reitor. Neste contexto, a dimensão seguinte irá tratar das decisões de investimentos dentro da universidade, segundo a percepção do reitor e pró-reitor de administração.

\subsection{Decisões de Investimentos da Universidade}

Partindo do pressuposto das decisões de investimentos, se questionou de quem parte as decisões em relação aos investimentos que são feitos na universidade, e para o pró-reitor de administração, todas as decisões são colegiadas, qualquer um pode enviar para os conselhos da universidade algum intensão de investimentos que se queira fazer. Já para o reitor, essas decisões são compartilhadas e em grande parte essas decisões advém da gestão superior, mas sempre em discussão com as direções de centro, sendo assim, a estrutura de governança da IES é verticalizada. 
Dentro deste contexto, se questiona se existem técnicas que garantem um processo ótimo para as decisões de investimentos. Para o pró-reitor de administração, as técnicas são padrões, na qual as propostas de investimento passam por todas as instâncias necessárias da universidade, priorizando sempre alguns tipos de investimentos (novas tecnologias, ampliação do espaço físico, novas equipamentos, formação de pessoal, etc.). Desse modo, existe um planejamento anual dos investimentos que serão feitos durante o ano e logo se decide as prioridades que serão dadas, reitera o reitor.

Ambos destacam que por ser uma universidade pública, existe uma execução orçamentaria a frente de toda questão contábil. A contabilidade da instituição é gerencial devido a prestação de contas, na qual deve-se seguir o orçamento. Por ser público, é preciso fazer o Plano Pruri Anual (PPA) com 4 anos de antecedência, tem ainda a Lei de Diretrizes Orçamentarias (LDO) que é feita no primeiro trimestre de cada ano, lembrando que é público municipal, na qual essa LDO está integrada com o orçamento da prefeitura. Ambos destacam que a universidade tem tido sucesso em relação ao que é projetado versus o que é realizado, mesmo com as instabilidades do cenário econômico.

Quando perguntado sobre que forma as decisões de investimentos contribuem para os fins institucionais, na percepção do reitor, todas as decisões são alinhadas ao Plano de Desenvolvimento Institucional (PDI), tendo sempre a visão e a missão como base. Por ser uma universidade pública, existem algumas restrições orçamentárias e de estrutura, na qual o reitor reitera, que caso precise fazer algum tipo de investimento de urgência em alguns casos deve-se pedir autorização ao poder legislativo do município. Embora a universidade possua uma autonomia muito grande no que tange a decisões é preciso da autorização do legislativo caso ela precise de um montante financeiro do Banco Nacional de Desenvolvimento Econômico e Social (BNDES), por exemplo, reitera o reitor e o pró-reitor.

Nesta dimensão, averiguou-se ainda se as decisões de investimentos geram uma vantagem competitiva para a instituição. Na visão do pró-reitor de administração a vantagem competitiva é pequena. Já nas palavras do reitor elas geram uma vantagem competitiva, e ele justifica argumentando que as decisões elas mantem, recuperam ou avançam em muitas áreas. Ambos destacam que a universidade tem uma preocupação com a infraestrutura, principalmente de laboratórios, pois é aí que vem o diferencial através da qualidade dos serviços prestados. Esses investimentos, todos são frutos de tomadas de decisões bem-feitas com a participação e colaboração de todos os envolvidos nestes processos. Para eles, os concorrentes (faculdades e centros universitários privados localizados no mesmo município) nenhum tem a infraestrutura 
que a universidade tem para prestar um serviço de qualidade, quando se trata de laboratórios equipados e profissionais qualificados.

Desse modo, complementando as discussões desta dimensão, a dimensão posterior, irá tratar do planejamento e do controle financeiro dentro da universidade, segundo a visão do reitor e do pró-reitor de administração.

\subsection{O Planejamento e o Controle Financeiro da Universidade}

Averiguou-se como funciona o planejamento financeiro e o controle da universidade, que para o reitor, existe na IES um órgão chamado Coordenadoria de Planejamento (COPLAN) na qual é a responsável por fazer as peças orçamentárias (planejamento financeiro) da universidade atendendo então o orçamento anual. No primeiro semestre e feito as diretrizes, já no segundo são feitos os detalhamentos do orçamento que posteriormente vem a compor orçamento da prefeitura municipal, que por seguinte é levado a câmara de vereadores do município para que seja aprovado. Todas estas partes do planejamento são discutido e tencionado em reuniões com os diretores dos centros e reitoria e deliberado futuramente pelo conselho universitário, segundo o reitor.

Os diretores de centro participam ativamente, pois eles representam as unidades da universidade (graduação, pós-graduação, etc.) sendo que, cada unidade possui um custo, na qual se chama PC (plano de custo). O processo, portanto, é centralizado na COPLAN que logo as peças orçamentárias advêm dos centros, que coletam dos departamentos, que coletam dos cursos e que coleta dos projetos. Quanto ao controle, para o reitor ele é feito em parte pela contabilidade e uma parte pela controladoria, cuja função é a cada bimestre fazer uma checagem em relação do que foi planejado foi executado em cima das metas que foram propostas. Logo a controladoria, com posse destes dados, fórmula indicadores de cada área da universidade, e mais recentemente a universidade vem sendo auditada pelo tribunal de conta do estado de Santa Catarina, sendo assim o controle e o planejamento da IES segundo o reitor e pró-reitor.

Quando perguntado sobre há existência de políticas institucionais que garantem um processo de planejamento e controle financeiro, o reitor destacou que sim, que é bem regrado na universidade na qual são sempre por instruções normativas ou por resoluções. Dentro de uma estrutura de governança quem controla o planejamento e o controle financeiro, para o reitor, ao longo do tempo vem se tentando mudar, pois é algo central, e da reitoria. Algumas 
propostas de reforma organizacional já tramitam na universidade, é que com isso, esse processo passe a ser de responsabilidade do conselho universitário, segundo o reitor.

A proposta se fundamenta pelo fato de a universidade não ter uma fundação e uma mantida, é uma estrutura só, dessa forma, o controle interno é monolítico do reitor. Com a proposta de ser controlado e examinado pelo conselho universitário os relatórios financeiros, visa-se apontar para o gestor as inconsistências e a praza para corrigi-las caso necessário, sendo assim uma forma mais transparente de controle, segundo o reitor e o pró-reitor de administração. Quanto aos mecanismos utilizados para avaliar o processo de planejamento e controle financeiro, segundo o reitor são avaliados a partir de uma análise do que foi projetado e o que foi realizado, sendo estes, mecanismos mais da feitura da peça orçamentária.

Já para o pró-reitor a comissão de avaliação interna (CPA) tem um papel importante na avaliação, pois lá está descrito as metas e objetivos a serem atingido pela universidade, na qual anualmente é revisto e visto o que foi atingido. A comissão faz o acompanhamento de toda a execução até a análise do balanço financeiro. Essa comissão se baseia em indicadores que o Ministério da Educação (MEC) e a Coordenação de Aperfeiçoamento de Pessoal de Nível Superior (CAPES) estabelece, na qual o PDI deve também estar alinhado a estes indicadores, reitera o pró-reitor.

Dessa forma, apurou-se se o processo de planejamento e controle financeiro está em conformidade com os objetivos institucionais, para o reitor sempre e reitera argumentando que é atrelado ao PDI a comissão própria de avaliação (CPA) com os objetivos do Sistema Nacional de Avaliação de Educação Superior (SINAES) e com o orçamento. E ressalta, que nada é feito sem que esses quatro pilares estejam interligados, e que são esses balizadores que orientam para a tomada de decisão e atingimento dos objetivos. Na visão do pró-reitor, todas as estratégias e processos de planejamento e de controle financeiro, são pensados, cujo objetivo é atingir a missão e a visão da universidade.

O processo de planejamento e controle financeiro gera uma vantagem competitiva para a universidade, para o reitor, no atual contexto é difícil argumentar se é mais vantajosa ou não, o que se pode dizer que o modelo existente na universidade é muito mais burocrático que as demais universidades de base comunitária. Do ponto de vista econômico, o processo de planejamento e controle financeiro gera uma vantagem competitiva, pelo fato de ter os números financeiros controlados, reitera o pró-reitor. Neste sentido, complementando as discussões desta dimensão, a próxima dimensão, irá tratar da liquidez, solvência e rentabilidade da universidade, segundo a visão do reitor e do pró-reitor de administração. 


\subsection{A Liquidez, a Solvência e a Rentabilidade da Universidade}

Quanto a liquidez, solvência e rentabilidade, se questionou de primeiro momento, como se encontra a liquidez da universidade, para o reitor e pró-reitor de administração, está absolutamente líquido do ponto de vista da sustentabilidade da gestão financeira para o ano de 2017/2018, com um índice de endividamento de 1\% em relação ao atual orçamento da universidade que chega na casa dos R $\$ 218$ milhões de reais. Este endividamento refere-se a uma dívida com o instituto de aposentadoria, para poder pagar o $13^{\circ}$ salário dos servidores, e assim fechar o caixa para o ano de 2017.

A tabela 1, pretende demostrar a evolução dos indicadores econômico-financeiros e orçamentário dos últimos quatro anos do exercício da universidade, na qual já estão publicados no domínio público (2013-2016).

Tabela 1: Indicadores econômico-financeiros e orçamentário (2013 - 2016)

\begin{tabular}{c|c|c|c|c|c}
\hline INDICADORES & FÓRMULA & $\mathbf{2 0 1 3}$ & $\mathbf{2 0 1 4}$ & $\mathbf{2 0 1 5}$ & $\mathbf{2 0 1 6}$ \\
\hline Liquidez Corrente & $\begin{array}{c}\text { Ativo Circulante/ } \\
\text { Passivo Circulante }\end{array}$ & 1,70 & 1,63 & 1,70 & 1,86 \\
\hline Liquidez Imediata & $\begin{array}{c}\text { Disponibilidades / } \\
\text { Passivo Circulante }\end{array}$ & 1,46 & 1,25 & 1,61 & 1,80 \\
\hline $\begin{array}{c}\text { Situação Financeira } \\
\text { Líquida }\end{array}$ & $\begin{array}{c}\text { Ativo Circulante - } \\
\text { Passivo Circulante / } \\
\text { Receita Total }\end{array}$ & $7,40 \%$ & $7,23 \%$ & $8,23 \%$ \\
\hline Evolução do Patrimônio & $\begin{array}{c}\text { PL Final / PL Inicial } \\
\text { Líquido }\end{array}$ & $1,09 \%$ & $0,99 \%$ & $1,02 \%$ \\
\hline Resultado Orçamentário & $\begin{array}{c}\text { Receita Orçamentária } \\
- \text { Despesa / Receita } \\
\text { Total }\end{array}$ & $0,06 \%$ & $(4,40) \%$ & $3,43 \%$ & $(0,31) \%$ \\
\hline
\end{tabular}

Fonte: Adaptado do relatório da controladoria geral da universidade (2018).

A interpretação dos indicadores apresentados na tabela 1, se dá da seguinte forma: Podese observar que a melhor Liquidez corrente dos 4 anos analisados, foi a do ano de 2016, na qual para cada $R$ \$ 1,00 de obrigações que a universidade tinha, a mesma possuía $R$ \$ 1,80 em espécie ou em direitos de alta liquidez para sua quitação. Numa série histórica, este índice vem se mantendo elevado para os anos analisados. Já em relação a liquidez imediata, índice que mesura a capacidade de pagamento de todos os compromissos de uma vez só, em 2016, para cada $\mathrm{R} \$$ 1,00 de dívida, a universidade possuía $\mathrm{R} \$ 1,80$ em espécie ou em direitos para sua quitação. Como pode ser observado na tabela 1, este índice vem se mantendo no mesmo nível. 
Quanto a situação financeira liquida, analisando os 4 anos, percebe-se que no ano de 2016, o superávit financeiro foi de $8,23 \%$ da receita total. Sendo assim, para cada $\mathrm{R} \$ 1,00$ de receita a universidade possuía $R \$ 0,08$ de superávit, recebeu $R \$ 0,08$ a mais do que gastou. A evolução do patrimônio líquido, na qual representa a diferença entre o ativo real e o passivo real, considerando a situação inicial e final dos períodos analisados, percebe-se uma diminuição em 2015 (0,99\%) e um aumento em 2016 (1,02\%). O Resultado orçamentário, demostra que em 2016 houve uma defasagem de 0,31\% das receitas, para cobertura das despesas, ou, ainda, que a execução da receita corresponde a 99,69\% da execução das despesas. Perante a isso, para cada $\mathrm{R}$ \$ 1,00 de execução orçamentária, adiciona-se mais $\mathrm{R}$ \$ 0,031 em seu déficit, tendo ao longo do tempo grandes oscilações neste índice.

Quanto ao valor do capital de giro da universidade, para os entrevistados, o giro é muito curto, com um fluxo de caixa que não pode ultrapassar os 60 dias sem recebimento. Neste caso, é preciso receber a receita para quitar as despesas, reitera o reitor. Quanto a solvência da universidade, para o reitor é uma universidade solvente, se manter com esse número de aluno. Para o pró-reitor de administração, seria preciso hoje de 9.000 alunos na graduação, que hoje conta com 8.500, para assim, ter uma folga financeira no caixa da universidade. O problema desta não folga financeira, acaba fragilizando os investimentos e a manutenção do patrimônio da universidade, que hoje está estimado em 1 bilhão de reais, reiteram os entrevistados.

Quanto o patrimônio líquido e a rentabilidade da universidade, segundo o pró-reitor, é muito próximo de zero. Quanto aos cursos que trazem maior rentabilidade para universidade, é na área da saúde de modo geral, sendo estes que trazem a maior margem de contribuição. De um outro lado, os que trazem menor rentabilidade, são das áreas humanas (licenciaturas), efeitos estes, que é um problema de mercado destas profissões, fazendo que haja uma baixa procura nestes cursos.

Portanto, no contexto geral, para os entrevistados, o caminho para uma sustentabilidade financeira da e das universidades, é olhar para o mercado, e verificar o que o mesmo está precisando, e assim delimitar e implementar estratégias para superar os desafios colocados pela competitividade do mercado. Sendo assim, o tópico seguinte, irá abordar as considerações finais, cujo objetivo é fazer o fechamento do estudo e propor futuras pesquisas nesta linha temática de trabalho, que envolve governança e gestão financeira. 


\section{CONSIDERAÇÕES FINAIS}

Ao longo do que foi exposto neste estudo, evidenciou-se a relevância do processo de governança e de gestão financeira no que tange a sua importância para o bom funcionamento da universidade. Assim sendo, é necessário que a universidade tenha uma governança bem estruturada bem como um processo de gestão financeira eficiente, com isso, é possível se obter algumas vantagens competitiva frente a outras IES que atuam na sociedade civil. Quanto aos objetivos projetados neste estudo, pode-se salientar que os mesmos foram atendidos em todas as suas dimensões. Vale salientar que está universidade, objeto de estudo, foi criada e é mantida por uma fundação incluída como órgão autônomo na estrutura administrativa do poder executivo municipal, sendo assim, uma instituição oficial de direito público.

Os principais resultados dizem respeito a obtenção de recursos financeiros da universidade, na qual se evidencio que $80 \%$ da receita da IES advém das mensalidades dos alunos e os outros $20 \%$ procura-se obter recursos através do artigo 170 e 171, financiamento estudantil - FIES além da prestação de serviço à comunidade civil. No que se refere a governança, a IES é descentralizada nos aspectos que tange as suas potencialidades, na qual tem em sua organização a gestão superior (Reitoria) na qual desenha as políticas macro e faz o controle dos processos financeiros. Quando se trata das vantagens competitiva da universidade, o estudo evidenciou-se que se gera muito pouca vantagem frente a outros grupos de ensino superior, reiterando ainda, que a universidade estudada gera muito conhecimento, muita inserção na sociedade, mas de resultado financeiro muito pouco.

Quanto as tendências do ponto de vista da gestão e da governança das universidades comunitárias/pública, este estudo evidenciou com a percepção dos entrevistados que há alguns caminhos. Um dos caminhos diz respeito a estrutura das universidades, na qual devem-se se moldar instituições com excelência na graduação, e fazer girar a potencialidade que a universidade possui em prestar serviços de qualidade (pesquisas, projetos etc.). Essa aproximação do mercado com a universidade rende bons resultados financeiros, mas é preciso trabalhar a cultura organizacional para que as coisas se desenrolem.

Quanto a universidade estudada, não é diferente, fortalecer e melhorar a graduação, novos projetos pedagógicos que contemple as necessidades dos seus alunos, pesquisa e comunidade através da extensão. Um caminho possível a ser vislumbrado pela universidade é na vertente política, com o protagonismo político pelo fato de a instituição ser pública municipal. Neste sentido, fazer com que o governo do estado veja que a universidade pode 
beneficiar ações estaduais de educação é uma saída. Dessa forma, a instituição poderia ser estadualizada e com isso não cairia numa vala comum como muitas universidades comunitárias estão caindo, sendo adiquiridas por grandes grupos de educação superior privada. Uma outra saída positiva para as universidades comunitária é atuar em cooperação, para assim poder competir e gerar vantagens frente as instituições privadas que não são comunitárias.

Quanto a atração e retenção dos alunos, a universidade estudada vem desenvolvendo uma série de estratégias que consequentemente vão impactar no que diz respeitoa gestão financeira da universidade. Uma das principais estratégias é a de postergar o período de pagamento das mensalidades por parte dos alunos. Sendo assim, a universidade começa a fazer um financiamento próprio, não necessitando a partir daí que o aluno recorra a bancos para pagar suas mensalidades. Com este mecanismo, aos poucos a universidade começa a financiar parte dos cursos de seus alunos, e com o tempo o ciclo se fecha, e assim começa a retroalimentação do sistema, possibilitando com que mais pessoas se beneficiem. Uma das estratégias para a atração de alunos é a flexibilização no número de créditos além de uma massiva divulgação frente a comunidade, divulgando as atividades que a universidade desempenha, e a qualidade que está inserida em cada serviço prestado. Estas são algumas das ações que a universidade vem desempenhando tendo como fonte destas informações, as entrevistas com o reitor e próreitor de administração.

Neste contexto, tem-se como proposições para futuras pesquisas um estudo comparativo que avalie estas dimensões analisadas com outras universidades comunitárias, com receita privada (FURB), IES comunitária com receita privada (UNIVILLE) e IES comunitária pública com receita pública (UDESC). Com um estudo avaliando o processo de governança e de gestão financeira das três instituições, seria possível inferir se o caminho e as ações que ambas projetam e executam possuem alguma similaridade e quanto estrutura de governança o que muda uma em relação a outra.

\section{REFERENCIAS}

ANDRADE, A.; ROSSETTI, J. P. Governança Corporativa: fundamentos, desenvolvimento e tendências. 5a . ed. São Paulo: Editora Atlas, 2011.

BERLE, A.; MEANS, G. The Modern Corporation and Private Property. Corporate

Governance - An International Review, Vol. 1, pp. 236-239. 1932. 
BRASIL. Constituição da República Federativa do Brasil, 1988. Brasília: Presidência da República. Disponível em: < http://www.planalto.gov.br/ccivil_03/constituicao/constituicao.htm>. Acesso em: 21 de junho de 2020.

BRASIL. Lei de no 9.637 de 15 de maio de 1998. Disponível em: http://www.planalto.gov.br/ccivil_03/leis/19637.htm\#: :text=LEI\%20N\%C2\%BA\%209.637 \%2C\%20DE\%2015\%20DE\%20MAIO\%20DE\%201998.\&text=Disp\%C3\%B5e\%20sobre\%2 0a\%20qualifica\%C3\%A7\%C3\%A3o\%20de,sociais\%2C\%20e \%20d\%C3\%A1\%20outras\%20 provid\%C3\%AAncias. Acesso em: 21 de junho de 2020.

BUSH, T. Educational leadership and management: Theory, policy and practice. South African Journal of Education, v. 27, n. 3, p. 391-406, 2007.

BUSH, T.; HEYSTEK, J. School Governance in the New South Africa, Compare: A Journal of Comparative and International Education, p. 127-138, 2003.

FOLETTO, P. R.; TAVARES, S. M. N. Especificidades da governança universitária: alguns aspectos. Gestão Universitária: Os Caminhos para a Excelência, p. 153, 2014.

GIL, A. C. Como elaborar projetos de pesquisa. (6. ed.) São Paulo: Atlas, 2017.

HILB, M. A nova governança corporativa: ferramentas bem-sucedidas para conselho de administração. São Paulo: Saint Paul Editora, 2009.

Instituto Brasileiro de Governança Corporativa (IBGC). Código das Melhores Práticas de Governança Corporativa, 2009.

JESSOP, B. The rise of governance and the risks of failure: the case of economic development. International Social Science Journal, v. 50, n. 155, p. 29-45, 1998.

KOOIMAN, J.; VAN VLIET, M. Governance and public management In: Eliassen, K.-J. Kooiman (eds.): Managing Public Organisation. 1993.

MESTRY, R. The role of governing bodies in the management of financial resources in South African no-fee public schools. Educational Management Administration \& Leadership, v. 46, n. 3, p. 385-400, 2018.

MEYER JR, V. A prática da administração universitária: contribuições para a teoria. Revista Universidade em Debate, v. 2, n. 1, p. 12-26, 2014.

QUEIROZ, J. V.; QUEIROZ, F. C. B. P.; HÉKIS, H. R. Gestão estratégica e financeira das Instituições de ensino superior: um estudo de caso. Iberoamerican Journal of Industrial Engineering, v. 3, n. 5, p. 98-117, 2011.

RAUPP, F. M.; BEUREN, I. M. Metodologia da Pesquisa Aplicável às Ciências. Como elaborar trabalhos monográficos em contabilidade: teoria e prática. São Paulo: Atlas, 2006. 
RODRÍGUEZ-PONCE, E et al. La relación entre la gestión financiera y la calidad en las instituciones de educación superior. Interciencia, v. 42, n. 2, 2017.

SATHLER, L. Governança no terceiro setor: estudo descritivo-exploratório do comportamento de conselhos curadores de fundações empresariais no Brasil. Tese de Doutorado. Tese (Doutorado)-Universidade de São Paulo, São Paulo, São Paulo, Brasil, 2008.

SILVA, R. C. F da et al. The Governance's role in Strategic Process: A Study in an Organization with no Economic Purpose. Business and Management Review. V. 5, n.1, p. $198-2009,2015$.

SILVEIRA, A. D. M. Governança corporativa no Brasil e no mundo. Rio de Janeiro: Elsevier, 2010.

SLOMSKI, V et al. Governança Corporativa e Governança na Gestão Pública. São Paulo: Atlas, 2008.

TAVARES, S. M. N. Governança em universidades confessionais no Brasil: modelo em construção. Educação \& Linguagem, v. 12, n. 19, p. 219-238, 2009.

TAYLOR, M. P. What is good university financial management? Perspectives: Policy and Practice in Higher Education, v. 17, n. 4, p. 141-147, 2013. 